\title{
Patient-Related Risk Factors for the Development of Lumbar Spine Adjacent Segment Pathology
}

Eduardo Moreira Pinto, Artur Teixeria, Richado Frada, Filipa Oliveira, Pedro Atilano, Tânia Veigas, António Miranda

Keywords: sagittal alignment, lumbar spine, adjacent segment disease, adjacent segment degeneration, adjacent segment pathology

https://doi.org/10.52965/001c.24915

\section{Orthopedic Reviews}

Vol. 13, Issue 1, 2021

\begin{abstract}
Objectives
Individual risk factors for the development of adjacent segment pathology (ASP) need to be investigated and identified to address possible modifiable factors in advance and improve outcomes and reduce medical costs. This study aimed to review the literature regarding patient-related risk factors and sagittal alignment parameters associated with ASP development.
\end{abstract}

\section{Methods}

The authors performed an extensive review of the literature addressing the objectives mentioned earlier.

\section{Results \\ Certain patient factors such as age, gender, obesity, preexisting degeneration, osteoporosis, postmenopausal state, rheumatoid arthritis, and facet tropism may contribute to adjacent segment degeneration. Genetic influences, such as polymorphisms of the vitamin D receptor and collagen IX genes, can also be a potential cause for disc degeneration with consequent deterioration of the motion segment. \\ The influence of sagittal imbalances, particularly after lumbar fusion, is a significant parameter to be taken into account as an independent risk factor for ASP development.}

\section{Conclusions}

Patient-specific risk factors, such as age, gender, obesity, preexisting degeneration, and genetic features increase the likelihood of developing ASP. On the other hand, sagittal alignment plays a significant role in the development of this condition.

\section{INTRODUCTION}

Most studies define adjacent segment disease (ASD) as the clinical translation of the radiographic changes associated with adjacent segment degeneration (ASD). However, there is no validated outcome measurement to diagnose or quantify ASD. ${ }^{1-4}$ Some authors, such as Lee et al., 5 consider reoperation rate as the most reliable parameter for the definition of ASD and recommended its use as the primary criterion to define adjacent segment pathology. Indeed, the "classic" definition of ASD does not always warrant revision surgery, either due to patient comorbidities and preferences, surgeon reluctance, or effective conservative treatment. ${ }^{6-8}$

An increase in mechanical stresses after fusion may lead to an increase in ASDeg and ultimately to the development of ASD. The rate of changes from adjacent segment degeneration generally manifests 5 to 10 years after surgery. The development of adjacent segment pathology following lumbar fusion is a significant cause of revision surgery. ${ }^{1}$ At ten years of follow-up, about $25 \%$ of patients undergoing short lumbar fusion will develop ASDeg. ${ }^{9}$ Ghiselli et al. ${ }^{10}$ predicted a 10 -year prevalence of ASDeg of $36.1 \%$, with $27.4 \%$ of the patients in their cohort requiring adjacentlevel surgery.

Previous studies have identified several individual risk factors associated with ASD such as age, gender, obesity, preexisting degeneration, rheumatoid arthritis, and genetic factors, including polymorphisms of the vitamin D receptor and collagen IX genes. ${ }^{11-13}$

The etiology of ASD has also been related to changes following spinal fusion that irreversibly alter the normal biomechanics of the spine by eliminating motion at the fused segment, which causes enhanced mechanical stress at the adjacent segments with the subsequent hastening of degenerative changes. ${ }^{12-14}$ The relationship between sagittal balance, spinopelvic parameters, and lumbar lordosis is essential for the sagittal profile of the spine and, if not corrected, can promote an imbalance that leads to the development of ASD.

The ability to determine a patient's risk factors for the development of ASD is extremely important since they may be modifiable factors that, if corrected, can improve outcomes and alleviate medical costs. This study proposes to 
review the literature regarding individual risk factors and sagittal alignment parameters associated with the development of ASD.

\section{ETIOLOGY}

Due to the multifactorial etiology of ASD, correlating singular variables and their potential impact on the development of this pathology is difficult. The risk factors for ASD development can be separated into patient-related factors and surgical factors, directly modified by the surgeon during the procedure. ${ }^{15-19}$ Certain patient factors such as age, gender, obesity, preexisting degeneration, osteoporosis, postmenopausal state, rheumatoid arthritis, and facet tropism may contribute to adjacent segment degeneration. $1,15,20,21$

Genetic influences, such as polymorphisms of the vitamin D receptor and collagen IX genes, can also be a potential cause of disc degeneration with consequent deterioration of the motion segment. ${ }^{11}$ Alentado et al. ${ }^{22}$ reported an association between coronary artery disease and the development of ASD. Other medical comorbidities, including hypertension, hyperlipidemia, diabetes, smoking history, current smoking status, preoperative ASA grade, pain level, and duration of symptoms before the operation, were not significantly correlated with the development of ASD. ${ }^{22}$

\section{THE INFLUENCE OF BODY MASS INDEX (BMI)}

BMI is an important independent predictor of back pain. Its severity is associated with the degree of dissatisfaction and outcomes after surgery for lumbar spinal stenosis and the rate of lumbar spine reoperations. ${ }^{23,24} \mathrm{~A} \mathrm{BMI}$ increment leads to the increased loading on the lumbar spine that causes the intervertebral disks to lose height and ability to absorb forces, resulting in abnormal loading on surrounding facet joints, spinal ligaments, and paraspinal muscles. ${ }^{25-28}$

In overweight or obese patients, as there is an increase in BMI not accompanied by muscle hypertrophy, the paraspinal musculature decreases its support capacity to maintain an upright posture, which leads to an increase in intradiscal pressure and segmental motion after lumbar fusion, creating a larger body mass that potentially adds more stress to the adjacent levels and accelerates the degenerative process. ${ }^{29}$ As a result, BMI maybe not only is a factor related to the natural degeneration of healthy spines but may also play an important role in ASD. ${ }^{29}$ Studies from Symmons et al. ${ }^{30}$ and Liuke et al. ${ }^{31}$ provided evidence that BMI greater than $25 \mathrm{~kg} / \mathrm{m}^{2}$ increases the risk of lumbar disc degeneration. In a retrospective study including 190 patients after lumbar fusion for degenerative spine disease, $\mathrm{Ou}$ et al. ${ }^{32}$ found body mass index to be a risk factor for ASD. Because BMI is a clinically objective and modifiable variable, control of body weight can be an excellent variable to optimize during a patient's preoperative period that could enhance fusion surgery outcomes.

\section{AGE AND ASD}

It remains controversial if there is an association between age and adjacent segment disease.

As the spine ages, the degenerative cycle will progres- sively modify functional anatomy, creating a rupture of stability, equilibrium, and proprioception. Aging is also associated with a decrease in spine flexibility and capacity in accommodating biomechanical alterations after fusion.

Some researchers have reported an increased incidence of ASD with advancing age.7,33,34 In a retrospective series of 490 patients, Lee et al. ${ }^{7}$ reported that patients older than 60 were more likely to have ASD requiring surgery. Cheh et al. ${ }^{16}$ and Sears et al. ${ }^{9}$ also found that age greater than 50 or 60 years was correlated with a greater prevalence of ASD. Effectively, most studies have shown an increase of ASD incidence with advancing. ${ }^{7,35-40}$ However, some studies have reported no correlation between ASD and age. ${ }^{41-43}$

\section{PREOPERATIVELY ADJACENT LEVEL DEGENERATION AND THE POTENTIAL DEVELOPMENT OF ASD}

The absence of preoperative adjacent level degeneration also seems to have a relevant influence on the potential development of ASD. Lee et al. ${ }^{38}$ determined that preexisting facet degeneration is associated with a high risk of ASD. In a prospective study including patients who underwent instrumented fusion for degenerative disease, Anandjiwala et al. ${ }^{20}$ demonstrated an increased risk for developing ASDeg in patients with previous disc degeneration. In a retrospective study including 237 patients, Wang et al. ${ }^{44}$ stated that preoperative disc degeneration at the adjacent level was significantly and independently associated with ASD. It has been confirmed by both clinical case studies and biomechanical analysis that postoperative ASDeg develops more frequently in patients who have advanced disc degeneration preoperatively. ${ }^{20,42,45,46}$ Furthermore, rates of ASD are lower in patients who underwent fusion for trauma or are congenitally fused, supporting the hypothesis that preexisting disease is a significant factor in ASD etiology rather than a long-term sequel from surgical intervention. ${ }^{47,48}$

\section{INTRADISCAL PRESSURE AND ASD}

Changes in intradiscal pressure (IDP) can have multiple causes and are associated both with patient factors (e.g., BMI and natural degenerative process of the spine) and spine biomechanics, as well with the type and length of fusion. ${ }^{14}$ The increase of IDP blocks the diffusion of nutrients from the endplate, impairs disc nutrition, and is also reported as the most significant cause of disc degeneration. ${ }^{49,50}$

Many authors have investigated adjacent-level IDP changes after lumbar fusion. An increase in intradiscal pressure was proposed as an etiological factor for the development of ASD, ${ }^{51,52}$ with biomechanical studies showing increased IDP on the adjacent discs after a single-level fusion model. ${ }^{53,54}$ Cunningham et al. ${ }^{54}$ demonstrated a $45 \%$ increase in lumbar intradiscal pressures at motion segments cephalic to a fusion. This pressure was particularly high in flexion-extension when fusion was compared to total disc arthroplasty (TDA) and baseline. Primary spinal malalignment is also a risk factor for increased intradiscal pressure, leading to a greater risk for developing ASDeg in the lumbar spine. ${ }^{55-59}$ 


\section{THE INFLUENCE OF SAGITTAL ALIGNMENT}

The pelvis is the cornerstone of sagittal spinal alignment. The revolutionary concept by Jean Dubousset's that "the entire pelvis is a vertebra" was the beginning of numerous investigations on the relationship between pelvic morphology and sagittal spinal alignment. Sagittal alignment, often misrepresented as sagittal balance, describes the ideal and "normal" alignment in the sagittal plane, resulting from the symbiosis between various organic factors, with pelvic morphology considered its foundation.

\section{SAGITTAL BALANCE}

Several studies have described the relationship between sagittal radiographic parameters and Health-Related Quality of Life (HRQOL) scores. ${ }^{60-65}$ It has been proven that sagittal balance is among the most reliable factors influencing ASD development. ${ }^{36}$ In 2005, Glassman and colleagues $^{66}$ demonstrated a significant correlation between positive sagittal balance and patient-reported self-assessment measures, notably between increased positive sagittal imbalance and symptoms aggravation. Kumar et al. ${ }^{36}$ concluded that patients with an average postoperative C7 plumbline and sacral inclination had the lowest risk of adjacent segment degeneration. Effectively, sagittal spinal alignment, especially maintaining the normal spinopelvic relationship, is essential for preventing ASD after interbody fusion.

\section{LUMBAR LORDOSIS}

Lumbar lordosis (LL) is a critical feature of spinal morphology which correlates with the risk of developing ASD. 67,68 The concept of maintenance of lumbar lordosis following fusion as a protective factor to the risk of developing adjacent segment stress and instability was described by several authors such as Hioki et al. ${ }^{58}$ and Chen et al. ${ }^{69}$ A recent study ${ }^{70}$ published in 2018 was the first to analyze the influence of LL on the biomechanical characteristics of the adjacent segment after L4-L5 TLIF. The results showed that as LL decreases, the stress of the adjacent disc increases. In conclusion, hypolordosis appears to increase the risk of adjacent segment deterioration. ${ }^{71,72}$

\section{PELVIC INCIDENCE AND ITS RELATIONSHIP WITH LUMBAR LORDOSIS}

Pelvic incidence (PI) is strongly correlated with various pelvic and spinal positional parameters and is a useful predictor of LL. Boulay et al., ${ }^{73}$ in a prospective study from 2005 including 149 patients, proposed an equation to predict LL based on PI and explored the conditions of an "economic posture.” PI has subsequently been generally acknowledged as a predictor of the amount of LL required to assume a balanced sagittal alignment. ${ }^{61,74}$ Lafage and colleagues $^{75}$ further refined this idea, demonstrating that PI matches LL and that increasing pelvic retroversion directly correlates with worsening patient-reported quality-of-life measures. These observations currently remain as the cornerstones of adult spinal deformity surgery and define the goals of reconstructive surgery, with the formulas of the sagittal vertical axis (positive/negative) $<20$ degrees and LL $=\mathrm{PI} \pm 9$ degrees being considered to provide the optimal balance values, associated with good patient-centered clinical status. ${ }^{61}$ Schwab et al., ${ }^{61}$ in a study by authors of the International Spine Study Group, emphasized the relevance of pelvic incidence-lumbar lordosis (PILL) mismatch as an intrinsic part of the adult deformity and its restoration as the primary objective in the surgical management of adult deformity.

Effectively, the restoration of the relationship between LL and PI seems essential for postoperative outcomes as it accounts for different loading patterns in the lumbar spine, which may be relevant for the development of ASD. In a multivariate analysis, ${ }^{75}$ a high PI was a risk factor for adjacent segment degeneration development. Moreover, Rothenfluh et al. ${ }^{76}$ reported that patients who required reoperation for ASD are ten times more likely to have a PI and LL mismatch greater than 10 degrees. Thus, PI and LL imbalances are essential parameters to consider as risk factors for the development of ASD.

\section{PELVIC TILT}

Relative to pelvic tilt (PT), as it increases, it generates a posterior inclination of the pelvis, and a large PT is associated with increased pain and decreased function. ${ }^{77}$ There are not many references in the literature regarding the relationship between PT and ASD. In a recent study considering risk factors of ASD after TLIF in 263 patients, the risk was 5.1 times greater in subjects with preoperative PT of more than $22.5^{\circ} .^{68}$ Therefore, it is reasonable to conclude that intrinsic factors and altered biomechanics associated with sagittal imbalances play a synergistic role in developing ASD after a fusion procedure.

\section{CONCLUSIONS}

Adjacent segment disease is a problem with a well-studied causal effect but with poorly understood risk factors, including several individual factors, hereditary and acquired, and causes associated with the surgical procedure. From this review, we can conclude that several risk factors directly related to the patient (e.g., age, gender, obesity, preexisting degeneration, genetic influences) lead to an increased likelihood of developing ASD. On the other hand, sagittal alignment has an essential relevance in the development of this pathology.

\section{DECLARATION OF CONFLICTING INTERESTS}

The authors declared no potential conflicts of interest with respect to the research, authorship, and/or publication of this article.

\section{FUNDING}

The authors received no financial support for the research, authorship, and/or publication of this article. 
Submitted: June 01, 2021 EST, Accepted: June 18, 2021 EST 


\section{REFERENCES}

1. Park P, Garton HJ, Gala VC, Hoff JT, McGillicuddy JE. Adjacent segment disease after lumbar or lumbosacral fusion: Review of the literature. Spine. 2004;29(17):1938-1944. doi:10.1097/01.brs.00001370 $\underline{69.88904 .03}$

2. Xia XP, Chen HL, Cheng HB. Prevalence of adjacent segment degeneration after spine surgery: A systematic review and meta-analysis. Spine. 2013;38(7):597-608. doi:10.1097/brs.0b013e318273a2 ea

3. Hilibrand AS, Robbins M. Adjacent segment degeneration and adjacent segment disease: The consequences of spinal fusion? Spine $J$. 2004;4(6):S190-S194. doi:10.1016/i.spinee.2004.07.00 $\underline{7}$

4. Harrop JS, Youssef JA, Maltenfort M, et al. Lumbar adjacent segment degeneration and disease after arthrodesis and total disc arthroplasty. Spine. 2008;33(15):1701-1707. doi:10.1097/brs.0b013e31817 bb956

5. Lee JC, Lee SH, Peters C, Riew KD. Adjacent Segment Pathology Requiring Reoperation After Anterior Cervical Arthrodesis: The Influence of Smoking, Sex, and Number of Operated Levels. Spine. 2015;40(10):E571-E577. doi:10.1097/brs.00000000000 $\underline{00846}$

6. Chou D, Dekutoski M, Hermsmeyer J, Norvell DC. The treatment of lumbar adjacent segment pathology after a previous lumbar surgery: A systematic review. Spine. 2012;37(22):S180-S188. doi:10.1097/brs.0b013 e31826d613d

7. Lee JC, Kim Y, Soh JW, Shin BJ. Risk factors of adjacent segment disease requiring surgery after lumbar spinal fusion: Comparison of posterior lumbar interbody fusion and posterolateral fusion. Spine. 2014;39(5):E339-E345. doi:10.1097/brs.000000000000 $\underline{0164}$

8. Rajaee SS, Kanim LEA, Bae HW. National trends in revision spinal fusion in the USA: Patient characteristics and complications. Bone Joint J. 2014;96-B(6):807-816. doi:10.1302/0301-620x.96b6.3 $\underline{1149}$

9. Sears WR, Sergides IG, Kazemi N, Smith M, White GJ, Osburg B. Incidence and prevalence of surgery at segments adjacent to a previous posterior lumbar arthrodesis. Spine J. 2011;11(1):11-20. doi:10.1016/j.s pinee.2010.09.026
10. Ghiselli G, Wang JC, Bhatia NN, Hsu WK, Dawson EG. Adjacent segment degeneration in the lumbar spine. J Bone Joint Surg Am. 2004;86-A(7):1497-1503. doi:10.2106/00004623-200407000-00020

11. Chan D, Song Y, Sham P, Cheung KMC. Genetics of disc degeneration. Eur Spine J. 2006;15(S3):S317-S325. doi:10.1007/s00586-006-017 $1-3$

12. Bastian L, Lange U, Knop C, Tusch G, Blauth M. Evaluation of the mobility of adjacent segments after posterior thoracolumbar fixation: A biomechanical study. Eur Spine J. 2001;10(4):295-300. doi:10.1007/s0 $\underline{05860100278}$

13. Ekman P, Möller H, Shalabi A, Yu YX, Hedlund R. A prospective randomised study on the long-term effect of lumbar fusion on adjacent disc degeneration. Eur Spine J. 2009;18(8):1175-1186. doi:10.1007/s0058 $\underline{\text { 6-009-0947-3 }}$

14. Weinhoffer SL, Guyer RD, Herbert M, Griffith SL. Intradiscal pressure measurements above an instrumented fusion. A cadaveric study. Spine. 1995;20(5):526-531. doi:10.1097/00007632-19950301 0-00004

15. Aota Y, Kumano K, Hirabayashi S. Postfusion instability at the adjacent segments after rigid pedicle screw fixation for degenerative lumbar spinal disorders. J Spinal Disord. 1995;8(6):464-473. doi:10.1 $\underline{\text { 097/00002517-199512000-00008 }}$

16. Cheh G, Bridwell KH, Lenke LG, et al. Adjacent segment disease following lumbar/thoracolumbar fusion with pedicle screw instrumentation: a minimum 5-year follow-up. Spine. 2007;32(20):2253-2257. doi:10.1097/brs.0b013e31814 b2d8e

17. Etebar S, Cahill DW. Risk factors for adjacentsegment failure following lumbar fixation with rigid instrumentation for degenerative instability. $J$ Neurosurg. 1999;90(2):163-169. doi:10.3171/spi.199 9.90.2.0163

18. Kaito T, Hosono N, Mukai Y, Makino T, Fuji T, Yonenobu K. Induction of early degeneration of the adjacent segment after posterior lumbar interbody fusion by excessive distraction of lumbar disc space. $J$ Neurosurg Spine. 2010;12(6):671-679. doi:10.3171/200 9.12.spine 08823 
19. Okuda S, Iwasaki M, Miyauchi A, Aono H, Morita $\mathrm{M}$, Yamamoto T. Risk factors for adjacent segment degeneration after PLIF. Spine.

2004;29(14):1535-1540. doi:10.1097/01.brs.00001314 $17.93637 .9 \mathrm{~d}$

20. Anandjiwala J, Seo JY, Ha KY, Oh IS, Shin DC. Adjacent segment degeneration after instrumented posterolateral lumbar fusion: A prospective cohort study with a minimum five-year follow-up. Eur Spine J. 2011;20(11):1951-1960. doi:10.1007/s00586-011-19 $\underline{17-0}$

21. Park JS, Shim KD, Song YS, Park YS. Risk factor analysis of adjacent segment disease requiring surgery after short lumbar fusion: The influence of rheumatoid arthritis. The Spine Journal. 2018;18(9):1578-1583. doi:10.1016/j.spinee.2018.02.0 $\underline{05}$

22. Alentado VI, Lubelski D, Healy AT, et al. Predisposing Characteristics of Adjacent Segment Disease After Lumbar Fusion. SPINE. 2016;41(14):1167-1172. doi:10.1097/brs.00000000000 $\underline{01493}$

23. Knutsson B, Michaëlsson K, Sandén B. Obesity is associated with inferior results after surgery for lumbar spinal stenosis: A study of 2633 patients from the Swedish spine register. Spine. 2013;38(5):435-441. doi:10.1097/brs.0b013e318270b243

24. Rihn JA, Radcliff K, Hilibrand AS, et al. Does obesity affect outcomes of treatment for lumbar stenosis and degenerative spondylolisthesis? Analysis of the Spine Patient Outcomes Research Trial (SPORT). Spine. 2012;37(23):1933-1946. doi:10.1097/ brs.0b013e31825e21b2

25. Adams MA, Dolan P. Recent advances in lumbar spinal mechanics and their clinical significance. Clin Biomech. 1995;10(1):3-19. doi:10.1016/0268-0033(9 5) $90432-9$

26. Dunlop RB, Adams MA, Hutton WC. Disc space narrowing and the lumbar facet joints. J Bone Joint Surg Br. 1984;66-B(5):706-710. doi:10.1302/0301-620 $\underline{\mathrm{x} .66 \mathrm{~b} 5.6501365}$

27. Ranger TA, Newell N, Grant CA, et al. The role of the middle lumbar fascia on spinal mechanics: A human biomechanical assessment. Spine. Published online 2016.

28. Ge W, Cao DY, Long CR, Pickar JG. Plane of vertebral movement eliciting muscle lengthening history in the low back influences the decrease in muscle spindle responsiveness of the cat. J Appl Physiol. 2011;111(6):1735-1743. doi:10.1152/japplphy siol.00059.2011
29. Wang H, Ma L, Yang D, et al. The incidence and risk factors for the progression of proximal junctional kyphosis in degenerative lumbar scoliosis following long instrumented posterior spinal fusion. Medicine. 2016;95(32):e4443. doi:10.1097/md.00000000000044 43

30. Symmons DP, van Hemert AM, Vandenbroucke JP, Valkenburg HA. A longitudinal study of back pain and radiological changes in the lumbar spine of middleaged women. I. Clinical findings, II. Radiographic findings. Ann Rheum Dis. 1991;50(3):158-166. doi:1 $\underline{0.1136 / \operatorname{ard} .50 .3 .158}$

31. Liuke M, Solovieva S, Lamminen A, et al. Disc degeneration of the lumbar spine in relation to overweight. Int J Obes. 2005;29(8):903-908. doi:10.10 38/sj.ijo.0802974

32. Ou CY, Lee TC, Lee TH, Huang YH. Impact of body mass index on adjacent segment disease after lumbar fusion for degenerative spine disease. Neurosurgery. 2015;76(4):396-402. doi:10.1227/neu.0000000000000 627

33. Min JH, Jang JS, Jung B joo, et al. The clinical characteristics and risk factors for the adjacent segment degeneration in instrumented lumbar fusion. J Spinal Disord Tech. 2008;21(5):305-309. doi:1 $\underline{0.1097 / \mathrm{bsd} .0 \mathrm{~b} 013 \mathrm{e} 318142 \mathrm{~b} 960}$

34. Maragkos GA, Atesok K, Papavassiliou E. Prognostic factors for adjacent segment disease after L4-L5 lumbar fusion. Neurosurgery. Published online June 27, 2019. doi:10.1093/neuros/nyz241

35. Korovessis P, Repantis T, Zacharatos S, et al. Does Wallis implant reduce adjacent segment degeneration above lumbosacral instrumented fusion? Eur Spine J. 2009;18:830-840.

36. Kumar MN, Baklanov A, Chopin D. Correlation between sagittal plane changes and adjacent segment degeneration following lumbar spine fusion. Eur Spine J. 2001;10(4):314-319. doi:10.1007/s0058600002 $\underline{39}$

37. Lawrence BD, Wang J, Arnold PM, Hermsmeyer J, Norvell DC, Brodke DS. Predicting the risk of adjacent segment pathology after lumbar fusion: A systematic review. Spine. 2012;37:S123-S132. doi:10.1097/brs.0b 013e31826d60d8

38. Lee CH, Hyun SJ, Kim KJ, Jahng TA, Yoon SH, Kim HJ. The efficacy of lumbar hybrid stabilization using the DIAM to delay adjacent segment degeneration: An intervention comparison study with a minimum 2-year follow-up. Neurosurg. 2013;73(2):ons224-ons232. doi:10.1227/neu.0b013e3 $\underline{1828 \mathrm{e} 8 \mathrm{ddc}}$ 
39. Liang J, Dong Y, Zhao H. Risk factors for predicting symptomatic adjacent segment degeneration requiring surgery in patients after posterior lumbar fusion. J Orthop Surg Res. 2014;9(1):97. doi:10.1186/s13018-014-0097-0

40. Lu K, Liliang PC, Wang HK, et al. Reduction in adjacent-segment degeneration after multilevel posterior lumbar interbody fusion with proximal DIAM implantation. J Neurosurg Spine. 2015;23(2):190-196. doi:10.3171/2014.12.spine14666

41. Kim KH, Lee SH, Shim CS, et al. Adjacent segment disease after interbody fusion and pedicle screw fixations for isolated L4-L5 spondylolisthesis: A minimum five-year follow-up. Spine. 2010;35:625-634.

42. Kim JY, Ryu DS, Paik HK, et al. Paraspinal muscle, facet joint, and disc problems: Risk factors for adjacent segment degeneration after lumbar fusion. Spine J. 2016;16(7):867-875. doi:10.1016/j.spinee.201 6.03.010

43. Ghasemi AA. Adjacent segment degeneration after posterior lumbar fusion: An analysis of possible risk factors. Clin Neurol Neurosurg. 2016;143:15-18. $\underline{\mathrm{d}}$ oi:10.1016/i.clineuro.2016.02.004

44. Wang H, Ma L, Yang D, et al. Incidence and risk factors of adjacent segment disease following posterior decompression and instrumented fusion for degenerative lumbar disorders. Medicine. 2017;96(5):e6032. doi:10.1097/md.000000000000603 2

45. Lee CS, Hwang CJ, Lee SW, et al. Risk factors for adjacent segment disease after lumbar fusion. Eur Spine J. 2009;18(11):1637-1643. doi:10.1007/s00586-0 09-1060-3

46. Yan JZ, Qiu GX, Wu ZH, Wang XS, Xing ZJ. Finite element analysis in adjacent segment degeneration after lumbar fusion. Int J Med Robot. 2011;7(1):96-100. doi:10.1002/rcs.374

47. Goffin J, van Loon J, Van Calenbergh F, Plets C. Long-term results after anterior cervical fusion and osteosynthetic stabilization for fractures and/or dislocations of the cervical spine. J Spinal Disord. 1995;8(6):500-508. doi:10.1097/00024720-19951200 $\underline{0-00012}$

48. Lee MJ, Dettori JR, Standaert CJ, Ely CG, Chapman JR. Indication for spinal fusion and the risk of adjacent segment pathology: Does reason for fusion affect risk? A systematic review. Spine. 2012;37(suppl):S40-S51. doi:10.1097/brs.0b013e3182 $\underline{6 \mathrm{ca} 9 \mathrm{~b} 1}$
49. Urban JPG, Holm S, Maroudas A, Nachemson A. Nutrition of the intervertebral disc: Effect of fluid flow on solute transport. Clin Orthop Relat Res. 1982;170:296-302. doi:10.1097/00003086-19821000 $\underline{0-00039}$

50. Buckwalter JA. Aging and degeneration of the human intervertebral disc. Spine. 1995;20(11):1307-1314. doi:10.1097/00007632-19950 $\underline{6000-00022}$

51. Chang UK, Kim DH, Lee MC, Willenberg R, Kim $\mathrm{SH}$, Lim J. Changes in adjacent-level disc pressure and facet joint force after cervical arthroplasty compared with cervical discectomy and fusion. J Neurosurg Spine. 2007;7(1):33-39. doi:10.3171/spi-07/07/033

52. Anakwenze OA, Auerbach JD, Milby AH, Lonner BS, Balderston RA. Sagittal cervical alignment after cervical disc arthroplasty and anterior cervical discectomy and fusion: Results of a prospective, randomized, controlled trial. Spine. 2009;34(19):2001-2007. doi:10.1097/brs.0b013e3181b 03fe6

53. Dmitriev AE, Cunningham BW, Hu N, Sell G, Vigna F, McAfee PC. Adjacent level intradiscal pressure and segmental kinematics following a cervical total disc arthroplasty: An in vitro human cadaveric model. Spine. 2005;30(10):1165-1172. doi:1 $\underline{0.1097 / 01 . b r s .0000162441 .23824 .95}$

54. Cunningham BW, Kotani Y, McNulty PS, Cappuccino A, McAfee PC. The effect of spinal destabilization and instrumentation on lumbar intradiscal pressure: An in vitro biomechanical analysis. Spine. 1997;22(22):2655-2663. doi:10.1097/0 0007632-199711150-00014

55. Levin DA, Hale JJ, Bendo JA. Adjacent segment degeneration following spinal fusion for degenerative disc disease. Bull NYU Hosp Jt Dis. 2007;65(1):29-36.

56. Park JY, Cho YE, Kuh SU, et al. New prognostic factors for adjacent-segment degeneration after onestage $360^{\circ}$ fixation for spondylolytic spondylolisthesis: Special reference to the usefulness of pelvic incidence angle. I Neurosurg Spine. 2007;7(2):139-144. doi:10.3171/spi-07/08/139

57. Hwang SH, Kayanja M, Milks RA, Benzel EC. Biomechanical comparison of adjacent segmental motion after ventral cervical fixation with varying angles of lordosis. Spine J. 2007;7(2):216-221. doi:1 $\underline{0.1016 / j . s p i n e e .2006 .05 .018}$

58. Hioki A, Miyamoto K, Kodama H, et al. Two-level posterior lumbar interbody fusion for degenerative disc disease: Improved clinical outcome with restoration of lumbar lordosis. Spine J. 2005;5(6):600-607. doi:10.1016/j.spinee.2005.04.001 
59. Sudo H, Oda I, Abumi K, Ito M, Kotani Y, Minami A. Biomechanical study on the effect of five different lumbar reconstruction techniques on adjacent-level intradiscal pressure and lamina strain. J Neurosurg Spine. 2006;5(2):150-155. doi:10.3171/spi.2006.5.2.15 $\underline{0}$

60. Schwab FJ, Ungar B, Blondel B, et al. Scoliosis Research Society-Schwab adult spinal deformity classification: a validation study. Spine.

2012;37(12):1077-1082. doi:10.1097/brs.0b013e31823 $\underline{\mathrm{e} 15 \mathrm{e} 2}$

61. Schwab F, Patel A, Ungar B, Farcy JP, Lafage V. Adult spinal deformity-postoperative standing imbalance: how much can you tolerate? An overview of key parameters in assessing alignment and planning corrective surgery. Spine. 2010;35(25):2224-2231. doi:10.1097/brs.0b013e3181e e6bd4

62. Youssef JA, Orndorff DO, Patty CA, et al. Current Status of Adult Spinal Deformity. Glob Spine J. 2013;3(1):51-62. doi:10.1055/s-0032-1326950

63. Terran J, Schwab F, Shaffrey CI, et al. The SRSschwab adult spinal deformity classification: Assessment and clinical correlations based on a prospective operative and nonoperative cohort. Neurosurgery. 2013;73(4):559-568. doi:10.1227/neu.0 $\underline{000000000000012}$

64. Blondel B, Schwab F, Ungar B, et al. Impact of magnitude and percentage of global sagittal plane correction on health-related quality of life at 2-years follow-up. Neurosurgery. 2012;71(2):341-348. doi:10.1 227/neu.0b013e31825d20c0

65. Smith JS, Klineberg E, Schwab F, et al. Change in Classification Grade by the SRS-Schwab Adult Spinal Deformity Classification Predicts Impact on HealthRelated Quality of Life Measures: Prospective Analysis of Operative and Non-operative Treatment. Spine. 2013;38(19):1663-1671. doi:10.1097/brs.0b013 e31829ec563

66. Glassman SD, Berven S, Bridwell K, Horton W, Dimar JR. Correlation of radiographic parameters and clinical symptoms in adult scoliosis. Spine.

2005;30(6):682-688. doi:10.1097/01.brs.0000155425.0 4536.f7

67. Sun J, Huang H, Wang JJ, Fu NX. Sagittal Alignment as Predictor of Adjacent Segment Disease After Lumbar Transforaminal Interbody Fusion. World Neurosurg. 2018;110:e567-e571. doi:10.1016/j.wneu.2 $\underline{017.11 .049}$
68. Yamasaki K, Hoshino M, Omori K, et al. Risk Factors of Adjacent Segment Disease After Transforaminal Inter-Body Fusion for Degenerative Lumbar Disease. Spine. 2017;42(2):E86-E92. doi:10.10 97/brs.0000000000001728

69. Chen WJ, Lai PL, Tai CL, Chen LH, Niu CC. The effect of sagittal alignment on adjacent joint mobility after lumbar instrumentation--a biomechanical study of lumbar vertebrae in a porcine model. Clin Biomech. 2004;19(8):763-768. doi:10.1016/j.clinbiome ch.2004.05.010

70. Zhao X, Du L, Xie Y, Zhao J. Effect of Lumbar Lordosis on the Adjacent Segment in Transforaminal Lumbar Interbody Fusion: A Finite Element Analysis. World Neurosurgery. 2018;114:e114-e120. doi:10.101 6/j.wneu.2018.02.073

71. Bae JS, Lee SH, Kim JS, Jung B, Choi G. Adjacent segment degeneration after lumbar interbody fusion with percutaneous pedicle screw fixation for adult low-grade isthmic spondylolisthesis: Minimum 3 years of follow-up. Neurosurgery.

2010;67(6):1600-1608. doi:10.1227/neu.0b013e3181f9 $\underline{1697}$

72. Korovessis P, Repantis T, Papazisis Z, Iliopoulos P. Effect of sagittal spinal balance, levels of posterior instrumentation, and length of follow-up on low back pain in patients undergoing posterior decompression and instrumented fusion for degenerative lumbar spine disease: A multifactorial analysis. Spine. 2010;35(8):898-905. doi:10.1097/brs.0b013e3181d51e $\underline{84}$

73. Boulay C, Tardieu C, Hecquet J, et al. Sagittal alignment of spine and pelvis regulated by pelvic incidence: Standard values and prediction of lordosis. Eur Spine J. 2005;15(4):415-422. doi:10.1007/s0058 6-005-0984-5

74. Roussouly P, Gollogly S, Berthonnaud E, Dimnet J. Classification of the normal variation in the sagittal alignment of the human lumbar spine and pelvis in the standing position. Spine. $2005 ; 30(3): 346-353$. do $\mathrm{i}: 10.1097 / 01 . b r s .0000152379 .54463 .65$

75. Nakashima H, Kawakami N, Tsuji T, et al. Adjacent segment disease after posterior lumbar interbody fusion: Based on cases with a minimum of 10 years of follow-up. Spine. 2015;40(14):E831-E841. doi:10.1097/brs.0000000000000917

76. Rothenfluh DA, Mueller DA, Rothenfluh E, Min K. Pelvic incidence-lumbar lordosis mismatch predisposes to adjacent segment disease after lumbar spinal fusion. Eur Spine J. 2015;24(6):1251-1258. do $\mathrm{i}: 10.1007 / \mathrm{s} 00586-014-3454-0$ 
77. Lafage V, Schwab F, Patel A, Hawkinson N, Farcy

JP. Pelvic tilt and truncal inclination: Two key radiographic parameters in the setting of adults with spinal deformity. Spine. 2009;34(17):E599-E606. doi:1 0.1097/brs.0b013e3181aad219 